\title{
Can Information Technology Promote Academic Performance of School-aged Children? An Empirical Study Based on CEPS
}

\author{
Chao Fang, Bin Huang \\ Nanjing University of Finance and Economics, Nanjing, China
}

\begin{abstract}
It is inconclusive whether the information technology can promote academic performance of school-aged children. Based on the China Education Panel Survey data provided by the NSRC, we used the method of quasi-experimental of propensity score matching to discuss the net effect of information technology on academic achievements. We found that: i) A significant difference existed in the academic performance between urban and rural school-aged children. The urban students were superior to those from the rural areas, whereas no positive correlation was found between the educational level and family economic condition; ii) Family human capital stock and family size (single child families) were positively correlated with internet usage, but the academic pressure reduced the probability of family Internet usage; iii) PSM revealed the negative impact of information technology on students' achievements when stratified into urban versus rural, and poverty versus non-poverty. The improvement of Chinese and English was realized indirectly by changing reading habits, while mathematics was directly by taking effective learning time. Our findings implied that a three-party linkage among the government, the school, and the family is required to emphasize the instrumental rationality of the information technology, promote the formation of the Internet learning preference, and support the development of the information technology hardware.
\end{abstract}

Best Evid Chin Edu 2019; 2(2):209-227.

Doi: 10.15354/bece.19.ar1045

Keywords: Information technology; Academic achievement; Propensity score matching; Internet preference

Correspondence to: Chao Fang, College of Public Administration, Nanjing University of Finance and Economics, Nanjing, China.Email: 99288137@qq.com. 


\section{Introduction}

$\mathrm{T}$

HE popularization of information technology at the elementary and middle schools in China has been on the fast track after entering the 21 st century. The launch of "XiaoXiaoTong" program in 2001 ushered in a new era of comprehensive connection between elementary and middle schools and the internet. In that year, there were 3.67 million computers in elementary and middle schools nationwide, and the "student-computer ratio" was as high as 51:1. A total of 10,687 elementary and middle schools had internet access, which account for only $1.8 \%$ of the whole schools (Gu, et al., 2017). Until 2016, according to the data provided by the Ministry of Education of China, the internet access rate by elementary and middle schools nationwide reached $87.45 \%$, and the coverage rate of multimedia classrooms reached $64.29 \%$. Education informatization objectively resulted in the unbalanced distribution geographically of the supporting information technology (Liu, et al., 2018). From the data of the Special Supervision Report on National Education Informatization Work in 2016, there was a big regional gap in the internet access rate of elementary and middle schools between the eastern, central and western areas, as well as the rate of multimedia distribution. The internet access rate in the eastern was $94.61 \%$, which was $10 \%$ and $10.49 \%$ higher than the central and western regions, respectively. The rate of multimedia equipment in the eastern was $76.95 \%$, which was $11.69 \%$ and $24.83 \%$ higher than the central and western regions, respectively.

The polarization of information technology has caused both "information rich" and "information poor". Rich of information means the internet can be used to invest human capital in education, improve children's achievement, form a closed loop between information capital and the reproduction of human capital, causing use of Internet aggravates the unfair of educational results, these were called "digital divide" (Yang, et al., 2017). Furthermore, the popularity of information technology makes children from low-resource families get preferred access to information resources, i.e., entertainment versus learning. Children from the low-resources families may have higher preference of entertainment (OECD, 2015), which makes the information technology be an inhibitor for children's achievements. As a result, educational inequality has been further widened.

In view of the "digital divide", educational inequality and the uncertainty between information technology and academic achievements, we hereby designed this study to focus on the following three questions: First, if information technology could improve academic achievements of school-age children? Second, whether the using of computer and internet has different effect on students' academic achievements between urban and rural families? Third, if children from different economical backgrounds (poverty versus non-poverty family) could use information technology equally to

\footnotetext{
About the Author: Bin Huang, College of Public Administration, Nanjing University of Finance and Economics, Nanjing, China. Email: james7526@163.com.
}

Conflict of Interests: None. 
improve their academic abilities. In addition, our study helped to reach a consensus on the topic whether information technology can help children improve their academic achievements to get theoretical and practical implications (Chan, et al., 2017; Cheng, et al., 2016; Xin, et al., 2010).

\section{Research Design}

\section{Research Methods}

\section{Model Setting}

In order to test the causal relationship between information technology and school-age children's academic achievements, linear model is set up as below:

$$
E d u c_{i t}=\alpha+\beta_{1} \text { Internet }_{i t}+C_{i t}+\mu_{i t}
$$

In formula (1), $i$ and $t$ indicate the individual (child) and family, respectively. The explained variable $\left(E d u c_{i t}\right)$ represents the academic achievements of the child $i$ in family $t$. $C_{i t}$ represents the set of control variables that will affect the use of information technology by child $i$, containing family background variables and individual characteristic variables, $\mu_{i t}$ represents the residuals.

\section{Measurement Process}

Ordinary Least Square (OLS), the traditional research method, was generally used for observing the influence of information technology on the academic outcomes of schoolage children. This works through observing values in the treatment group as the "net effect" of the changes in children's academic achievements from the influence of information technology. This method can lead to self-selection bias and counterfactualselection bias. Because family providing children with a computer or internet is not a random selection process, but a factor is influenced by both characteristics of family (such as parents' economic capital, cultural capital, education decision preference) and individual child (such as gender and grade). This will produce a big difference between the treatment in which children were provided with computer/internet and the control in which no computer/internet was provided. Therefore, it is unavoidable for both selfselection and counterfactual estimation biases if we use OLS in such a situation. In order to accurately identify the "net effect" of computer and internet on the academic outcomes, Propensity Score Matching (PSM) - a method presented by Rosenbaum and Rubin (1985), will be used in this study to reduce the estimation bias.

PSM was used to find control group with similar individual and family characteristics as well as education decision for the treatment group. Meanwhile, the control group also was the counterfactual choice of the treatment group. Technically, PSM treats factors that affect family ownership of computers and internet as co-variables, and then estimates the probability of using the internet; therefore, the process of allocation can be regarded as approximately random. On the one hand, it can improve the preci- 
sion of data matching; on the other hand, children in different groups can be compared horizontally. The influence of information technology on the academic achievements of school-age children was marked as Average Treatment Effect (ATT).

$$
\mathrm{ATT}=\mathrm{E}\left\{E\left[E d u c_{1 i}-E d u c_{0 i} \mid D_{i}=1, p=\left(X_{i}\right)\right]\right\}
$$

In formula (2), Educ ${ }_{1 \mathrm{i}}$ and $\mathrm{Educ}_{0 \mathrm{i}}$ indicate children's academic achievements in those who had and did not have computer/internet, respectively. $\mathrm{D}_{\mathrm{i}}$ is the indicator function, expressed in dummy variable. If family $t$ has a computer or internet then $\mathrm{D}_{\mathrm{i}}=1$, otherwise $\mathrm{D}_{\mathrm{i}}=0 . \mathrm{p}\left(\mathrm{X}_{\mathrm{i}}\right)$ indicates the probability of child $i$ using internet for study. The selection of factors that affect children's use of internet - represented by $\mathrm{X}$ - is the key of PSM.

\section{Data}

\section{Sample}

We used the Chinese Educational Panel Survey (CEPS) data, which was conducted by the National Survey Research Center at Renmin University of China. Data collecting procedures were in multi-stage stratified probability proportional to size (PPS), including the 7th and 9th graders. Four stages were included, and a total of 438 classes in 112 schools from 28 national level units were sampled in probability proportionally, and approximately 20,000 students were involved. The primary analysis was based on the baseline of this survey, which was collected during the 2013-2014 academic year.

\section{Variable Processing and Summary Statistics}

According to the educational production function from Hanushek (1992), school, government, family, and peers were the four major factors that influence educational output. Academic achievement can be seen as a proxy indicator of education output, but it was interfered by the education level and location of the school. This means it does not have horizontal comparability. However, this survey has provided standardized scores of Chinese, Math, and English, facilitated our study. Children's academic achievements were measured by the standardized scores of the three subjects, which were set as the dependent variable. As shown in Table 1, the mean standardized scores of Chinese, Math, and English were 70.458, 70.380 and 70.450, respectively. The mean score of Chinese was higher than the Math and English by 0.078 and 0.008 points, respectively, which indicated that children's academic achievement in Chinese was slightly better than both Math and English.

The provision of computer and internet was an important identifying variable as well as the key to explore if information technology can improve the academic achievement of school-age children. Both sets of variables in equation (2) were composed of dummy variables with values of 0 or $1(0=$ no computer or internet, $1=$ have computer or internet). The families with computers but no internet accounted for $8.5 \%$, whereas the families with both computers and internet accounted for $60.8 \%$. Overall, 


\section{Table 1. Basic Statistical Information of Variables.}

\begin{tabular}{lllll}
\hline Variable Name & Mean & SD & Min & Max \\
\hline Chinese Score & 70.458 & 9.641 & 6.164 & 98.475 \\
\hline Math Score & 70.380 & 9.733 & 8.422 & 145.115 \\
\hline English Score & 70.450 & 9.707 & 11.349 & 104.833 \\
\hline Computer or Not & 0.085 & 0.279 & 0 & 1 \\
\hline Internet or Not & 0.608 & 0.488 & 0 & 1 \\
\hline Mother's Educational Level & 3.828 & 1.977 & 1 & 9 \\
\hline Father's Educational Level & 4.205 & 1.994 & 1 & 9 \\
\hline Educational Expectation & 6.740 & 1.656 & 1 & 10 \\
\hline Economic Conditions & 0.879 & 0.326 & 0 & 1 \\
\hline Family Size & 0.438 & 0.496 & 0 & 1 \\
\hline Gender & 0.504 & 0.50 & 0 & 1 \\
\hline Age & 14.559 & 1.240 & 12 & 18 \\
\hline Grade & 0.498 & 0.50 & 0 & 1 \\
\hline Household Register & 0.540 & 0.498 & 0 & 1 \\
\hline Minority & 0.915 & 0.288 & 0 & 1 \\
\hline Academic Pressure & 0.362 & 0.480 & 0 & 1 \\
\hline Preschool Education or Not & 0.80 & 0.40 & 0 & 1 \\
\hline
\end{tabular}

over half families provided information technology assistant tools for their children's learning or entertainment. Parents' education level, family education expectation, economic status, and family size were family characteristic variables. Among them, the level of parents' education was used to control the human and cultural capital in different families by measuring as an ordinal variable with value 1 to 9 , which represented as illiterate, elementary school, middle school, secondary school (technical school), vocational high school, high school, junior college, undergraduate, and postgraduate. The higher the level was, the higher the family human capital had. The average educational levels of mother and father were 3.828 and 4.205 , respectively, which indicated that mother's education level ranged from middle school to secondary school (technical school), and father's ranged from secondary school (technical school) to vocational high school. The expectation of family education was composed of ordinal variables with value 1 to 10 . The mean value was 6.740 , indicating that parents expected their children to have a degree between junior college and undergraduate.

The family economic condition was represented by a dummy variable with a value of 0 or 1 , which was used to control the economic capital of different families. Value 1 indicates poverty, namely the school-aged children thought their families were very poor, poor or general, whereas value 0 indicates non-poverty, i.e., the school-aged children thought their families were rich or very rich. In our study, the mean value was 0.879 that indicated that $87.9 \%$ of school-aged children thought their families were poor (poverty), but only $12.1 \%$ of school-aged children thought their families were rich (nonpoverty).

Family size was also represented by a dummy variable with a value of 0 or 1 and it was used to control the resource dilution or sibling competition effect in the use of information technology. Value 0 indicates non-one-child family and value 1 indicates 
one-child family. The mean value was 0.438 indicated that one-child families account for $43.8 \%$ of the whole sample and non-one-child families account for $56.2 \%$. Theoretically, children were more likely to use information technology tools to learn if their parents had higher education level, higher education expectation and better family conditions (Fang \& Huang, 2018).

Gender, age, grade, household registration, ethnicity, academic pressure, and preschool education were individual characteristic variables of school-aged children. Male and female children accounted for $50.4 \%$ and $49.6 \%$ respectively. The age ranged from 12 to 18 with an average of 14.6 years. Children in the grades 7 and 9 accounted for $50.2 \%$ and $49.8 \%$, respectively. About $91.5 \%$ were from the ethnicity of Han, and $8.5 \%$ were minorities. After eliminating invalid samples without household registration, we defined agricultural household registration as rural household, non-agricultural household registration (including resident household registration) as urban household, the children with either rural or urban household registration accounted for $54 \%$ or $46 \%$, respectively.

The perception of academic pressure was represented by a dummy variable with a value of 0 or 1 , which indicated children's response level to parents' education expectation. Value 0 indicated children under no pressure or a little pressure, and value 1 indicated children under pressure or a lot of pressure. About $36.2 \%$ children mentioned that their parents' education expectation caused pressure during their learning, but $63.8 \%$ children said no. Finally, $80 \%$ of the children have received preschool education and $20 \%$ have not.

Additionally, in order to solve problems mentioned above - if information technology affecting academic achievements varied with household registration and family economic conditions, we took household registration and family economic conditions as the base of stratification. And then the differences of Chinese, Math, and English scores between urban and rural, poverty and non-poverty samples were shown. In Table 2, the mean scores of Chinese, Math, and English in those with urban household were $70.563,70.432$, and 70.799, respectively, which were higher than children with rural household $(70.367,70.439$, and 70.152, respectively) by $0.196,0.096$ and 0.647 , respectively. The overall academic achievements of urban students were better than that of rural students, and they had obvious advantages in English. The scores of these three subjects in children from poverty families were $70.496,70.439$, and 70.471 , respectively, which were higher than those from rich family $(70.181,69.591$ and 70.229, respectively), showed that there was a difference in scores between children who came from the poverty and non-poverty families, but the evidence was not solid enough to prove a positive correlation between family economic conditions and academic outcomes.

\section{Results and Analysis}

\section{Factors That Influence the Information Technology Use}

Following the research design of quasi-experimental, the net effect of information technology on school-aged children's academic performance could be estimated based on 
Table 2. Sub-sample of Academic Achievement.

\begin{tabular}{lllllllll}
\multirow{2}{*}{ Score } & \multicolumn{2}{l}{ Urban Household } & \multicolumn{2}{c}{ Rural Household } & \multicolumn{2}{c}{ Poor Family } & \multicolumn{2}{c}{ Non-poor Family } \\
\cline { 2 - 9 } & Mean & SD & Mean & SD & Mean & SD & Mean & SD \\
\hline Chinese & 70.563 & 9.651 & 70.367 & 9.631 & 70.496 & 9.672 & 70.181 & 9.407 \\
\hline Math & 70.432 & 9.743 & 70.336 & 9.725 & 70.439 & 9.707 & 69.951 & 9.912 \\
\hline English & 70.799 & 9.523 & 70.152 & 9.853 & 70.471 & 9.695 & 70.299 & 9.795 \\
\hline Obs. & 7,437 & & 8,674 & & 14,172 & & 1,944 & \\
\hline
\end{tabular}

PSM, which were divided into two steps: Step 1, Logit model was used to estimate the influence of the covariates between the treatment and control groups on the utilization of information technology, namely the analysis of the relevant factors that affect the utilization of information technology; Step 2, on the basis of data balance, the abovematching strategies were used to identify the average treatment effect (ATE) of information technology on academic performance of different disciplines. Therefore, the Logit model was used first to estimate the factors that affect the usage of computers and internet. Then internet including computers was regarded as the identification variable. The estimation results are showed in Table 3.

Since the dependent variable of the Logit model was a dummy variable with value 0 or 1 , we only got the direction of effect of the explanatory variable on the explained variables according to the results. In order to get the probability value, we calculated the average marginal effect $(\mathrm{dy} / \mathrm{dx})$ of each variable on the basis of Logit estimation. It should be noted that all variables in Table $\mathbf{3}$ are average marginal effects except the intercept.

In terms of the whole sample, the human capital in the family characteristic variables was positively correlated with internet use. The probability value of internet use increased by $3.1 \%$ and $3 \%$ for mothers' and father's education, respectively. In terms of family capital, poverty exerted a negative effect on the computer use. For each unit value of the school-aged children's perception regarding whether their family were poor or not, the probability value of internet use reduced by $22.2 \%$. Internet use was negatively correlated with family size. The probability value of internet use of one-child families was $9.7 \%$ higher than that of non-one-child families. Regarding children's characteristics, the estimated value of grade variable was significantly positive, indicating that the probability value of internet use of children in the grade 9 was $12.7 \%$ higher than that of children in the grade 7; Compared with ethnic minorities, the probability value of internet use in Han children was 14.3 percentage points higher. The registration of rural household had a negative effect on internet use, which was significant at the level of $1 \%$. Academic pressure was also negatively correlated with internet use. When the perceived academic pressure increased by one unit, the probability value of internet use decreased by $2.4 \%$.

In terms of the urban and rural sub-samples, the estimated values of mothers' and fathers' education in rural samples were 1.1 and 1.9 percentage points higher than that in urban samples. The negative impact of family poverty on internet use of rural children was greater than that of urban children, whereas the positive impact of family 


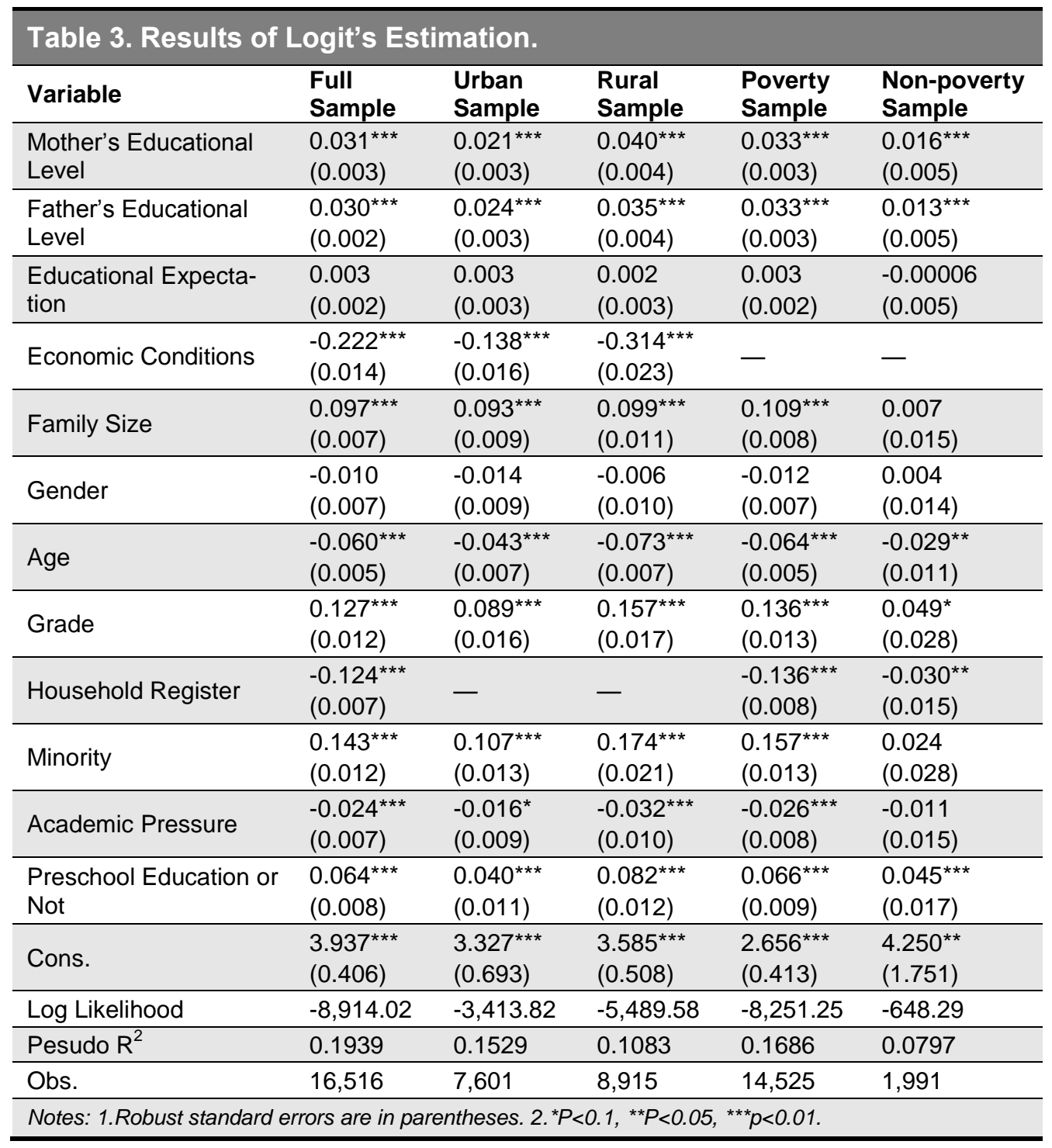

size on internet use was higher than that of urban children. These results indicated that there may be a binary division between urban and rural families in the information technology usage. The higher parents' educational expectation for their children, the higher the probability value of internet use, which is consistent with the theoretical hypothesis of this study, but the estimated value failed to find the significance. The possible reason is that the effect of educational expectation on internet use is not linear and direct, but indirectly moderates through some intervening co-founding variables.

In terms of poverty and non-poverty sub-samples, the average marginal effect of each variable was roughly the same in the value and direction of the parameter estimation. The difference only lied in the absolute value of the estimation. For example, the effect of parents' education on internet use was $3.3 \%$ and $3.3 \%$ in the poverty sam- 
ples, but $1.3 \%$ and $1.6 \%$ in the non-poverty samples. It was indicated that children from poverty families had a higher probability to use internet especially when their parents had higher education level compared with those from rich family. In terms of academic pressure perception, the estimate of the children from poor families was 0.026, which was 0.011 higher than children from the rich families. It was indicated that when academic pressure was perceived, children from poverty families were more likely to give up internet to study hard, which also showed that students' use of internet was more likely to meet their own entertainment preferences rather than learning. Due to the small sample size, the estimate of non-poverty samples was slightly less significant than that of poverty samples.

\section{The Impact of Information Technology on Academic Achievement}

\section{Balance Test of Covariates}

Based on the factor analysis of Logit model on the information technology usage, we further used PSM to estimate the "net effect" of computer and internet use on the academic achievements of school-aged children. In terms of technical processing, individuals in the treatment group and the control group were first paired. The propensity score of school-ages children who participated in the pairing was then calculated, therefore, the difference between the paired groups was the "net effect" of the treatment group, namely the ATE. In order to ensure the robustness of the estimation, we selected knearest Neighbor Matching, Radius (Caliper) Matching, Kernel Matching and Mahalanobis Matching as our matching strategies.

Before using the above-mentioned strategies to estimate the ATE, each covariable was ensured to be balanced. Therefore, the balance of each covariable was tested. In Table 4, columns 3 and 4 show the sample mean size (including before and after matching) in both groups. Column 5 shows standard errors of data before and after matching, which was the ratio of the sample mean difference of the two groups to the square root of the sample size. Columns 6 and 7 show the absolute value of the percentage deviation reduction and the $t$ value. According to Table 4, except for the increase of $94.4 \%$ in the standard error coefficient of gender variable, the standard error of other covariables all showed a decline trend at various degrees. The family size decreased most in standard error, which reached $99.2 \%$, but the grade variable had the smallest decline, decreased by $49.1 \%$. There were significant differences in each covariable before matching, while with a few variables statistically rejected the null hypothesis after matching. The t values of majority variables are not significant in statistics, i.e., the null hypothesis - treatment group and control group had no significant differences - cannot be refused. It indicated that the data matching eliminated significant differences of individual and family characteristics from different groups, which verified the rationality of matching method and covariate selection in this paper. This is also confirmed by the common value range of propensity score depicted in Figure 1.

\section{The Effect of Computer on Academic Achievement}




\begin{tabular}{|c|c|c|c|c|c|c|}
\hline Variable & Type & Treated & Control & \%Bias & $\begin{array}{l}\text { Reduct } \\
\text { |Bias| }\end{array}$ & $\mathbf{t}$ \\
\hline \multirow{2}{*}{ Mother's Educational Level } & Before & 4.396 & 2.970 & 79.7 & \multirow{2}{*}{97.7} & $47.72^{\star \star \star}$ \\
\hline & After & 4.392 & 4.359 & 1.9 & & 1.13 \\
\hline \multirow{2}{*}{ Father's Educational Level } & Before & 4.760 & 3.359 & 77.3 & \multirow{2}{*}{98.7} & $46.30^{\star \star \star}$ \\
\hline & After & 4.756 & 4.738 & 1.0 & & 0.60 \\
\hline \multirow{2}{*}{ Educational Expectation } & Before & 6.913 & 6.495 & 25.1 & \multirow{2}{*}{86.4} & $15.81^{* * *}$ \\
\hline & After & 6.912 & 6.969 & -3.4 & & $-2.59^{* \star *}$ \\
\hline \multirow{2}{*}{ Economic Conditions } & Before & 0.825 & 0.965 & -47.1 & \multirow{2}{*}{78.8} & $-27.36^{\star \star \star}$ \\
\hline & After & 0.825 & 855 & -10.0 & & $-5.71^{* \star *}$ \\
\hline \multirow{2}{*}{ Family Size } & Before & 0.557 & 0.259 & 63.6 & \multirow{2}{*}{99.2} & $38.87^{* \star *}$ \\
\hline & After & 0.556 & 0.558 & -0.5 & & -0.32 \\
\hline \multirow{2}{*}{ Gender } & Before & 0.498 & 0.507 & -1.7 & \multirow{2}{*}{-94.4} & -1.08 \\
\hline & After & 0.499 & 0.482 & 3.4 & & $2.37^{\star \star}$ \\
\hline \multirow{2}{*}{ Age } & Before & 14.394 & 14.791 & -32.0 & \multirow{2}{*}{91.6} & $-20.08^{\star \star \star}$ \\
\hline & After & 14.395 & 14.361 & 2.7 & & $2.00^{* *}$ \\
\hline \multirow{2}{*}{ Grade } & Before & 0.487 & 0.508 & -4.1 & \multirow{2}{*}{49.1} & $-2.55^{\star *}$ \\
\hline & After & 0.487 & 0.498 & -2.1 & & -1.47 \\
\hline \multirow{2}{*}{ Household Register } & Before & 0.411 & 0.738 & -70.1 & \multirow{2}{*}{96.6} & $-42.93^{\star \star \star}$ \\
\hline & After & 0.411 & 0.400 & 2.4 & & 1.57 \\
\hline \multirow{2}{*}{ Minority } & Before & 0.950 & 0.868 & 28.7 & \multirow{2}{*}{82.9} & $18.64^{\star \star \star}$ \\
\hline & After & 0.949 & 0.964 & -4.9 & & $-4.82^{\star \star \star}$ \\
\hline \multirow{2}{*}{ Academic Pressure } & Before & 0.333 & 0.403 & -14.4 & \multirow{2}{*}{92.9} & $-8.98^{\star \star *}$ \\
\hline & After & 0.333 & 0.338 & -1.0 & & -0.73 \\
\hline \multirow{2}{*}{ Preschool Education or Not } & Before & 0.853 & 0.720 & 32.8 & \multirow{2}{*}{87.3} & $20.87^{* \star *}$ \\
\hline & After & 0.852 & 0.869 & -4.2 & & -3.43 \\
\hline
\end{tabular}

\section{Figure 1. Common Range of Tendency Score.}

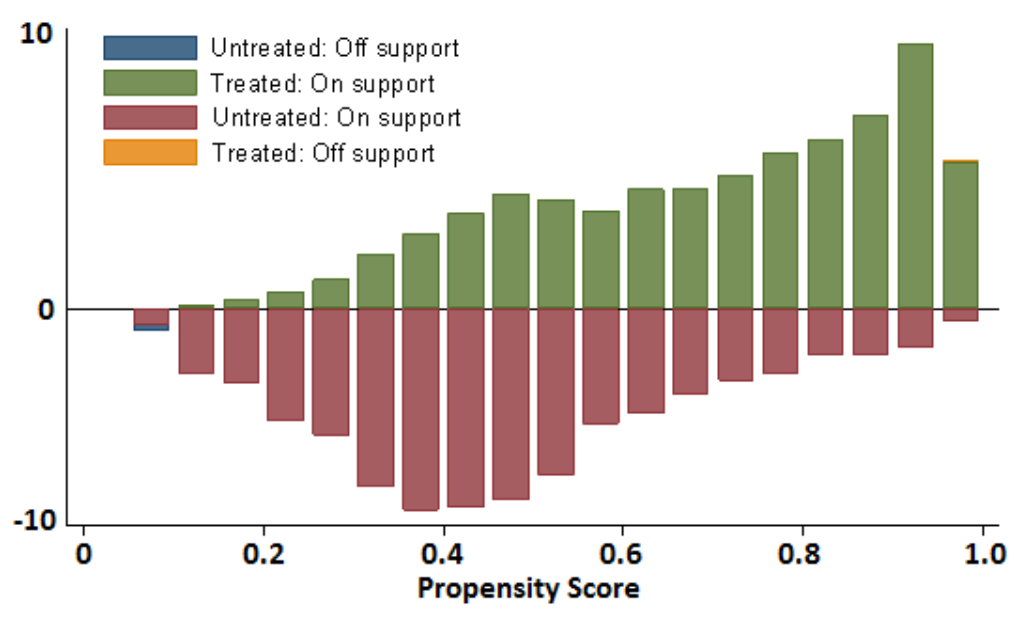


In order to ensure the robustness of the estimation results, we used k-nearest Neighbor Matching, Radius (Caliper) Matching, Kernel Matching, and Mahalanobis Matching on the basis of the covariate balance test, to accurately identify the "net effect" of computer usage on Chinese, Math, and English scores. In the k-nearest Neighbor Matching, set k $=4$, which used one-to-four matching; Radius was less than 0.01 in Radius (Caliper) Matching; Kernel function and bandwidth were defaulted in Kernel Matching. A method of handling heteroscedasticity robust standard error has been used in Mahalanobis Matching, which was indicated by Adabie and Imbens (2006).

According to the Table 5, the results of the k-nearest neighbor matching showed that the Chinese, Math, and English scores of the treatment group were 69.748, 70.20 , and 70.015, respectively, before the matching, but were 70.524, 79.397, and 70.491 , respectively for the control group. The differences between the two groups were 0.776, 0.197, and 0.476, respectively, of which the differences in Chinese and English scores were negatively significant at levels of $1 \%$ and $10 \%$. After the matching, the differences were $0.734,0.131$, and 0.241 , respectively, which reduced by $0.042,0.066$, and 0.235 , respectively, compared with prior-matching ones. The results showed that after adjusting the self-selection and counterfactual bias of family and individual characteristics by PSM, the negative effect of computer use on academic achievements was significantly reduced, indicating that ignoring the self-selection and counterfactual bias would overestimate the negative effect of computer use on academic achievements.

According to the estimation results of k-nearest neighbor matching, internet use had a negative effect on children's academic achievements. That is to say, compared with families without computers, the use of computers cannot help school-aged children improve but inhibit their academic level. Our results suggested that school-aged children may have two preferences for computer use - learning and entertainment. Given the sample was only from the 7th and 9th graders, and children in grade 7 and 9 were still in the formation and development period of cognitive and non-cognitive abilities, and their self-control ability was weak. In this case they are more likely to use computer for entertaining rather than for learning, which may be the major cause for the computer/internet use for negative academic achievements. In addition, when computers were used to meet their entertainment needs, it definitely caused a lack of effective learning time, which was another reason for the formation of negative causal relationship.

In terms of the estimation results of different disciplines, the negative effect of computer use on Chinese performance was higher than that on Math and English, and the negative effect on English performance was higher than that on Math. This partially showed that information technology had an exogenous impact on traditional reading methods and habits. Since the cultivation of students' understanding, the ability relies more on paper reading habits in Chinese teaching. The dependence of school-aged children on computer and paperless reading habits was not conducive to enhancing their understanding. This is the reason why the computer use has the most significant negative effect on Chinese performance.

Compared with Chinese, Math learning relies more on the construction of logic and deduction ability, computer use itself does not affect the development of logic, 


\begin{tabular}{|c|c|c|c|c|c|c|}
\hline Strategy & Score & Type & Treated & Control & ATT & T-stat \\
\hline \multirow[t]{6}{*}{ k-nearest Neighbor } & \multirow{2}{*}{ Chinese } & Before & 69.748 & 70.524 & $-0.776^{\star \star \star}$ & -2.85 \\
\hline & & After & 69.748 & 70.481 & $-0.734^{\star \star}$ & -2.40 \\
\hline & \multirow{2}{*}{ Math } & Before & 70.20 & 70.397 & -0.197 & -0.72 \\
\hline & & After & 70.20 & 70.331 & -0.131 & -0.43 \\
\hline & \multirow{2}{*}{ English } & Before & 70.015 & 70.491 & $-0.476^{*}$ & -1.74 \\
\hline & & After & 70.015 & 70.255 & -0.241 & -0.77 \\
\hline \multirow[t]{6}{*}{ Radius } & \multirow{2}{*}{ Chinese } & Before & 69.748 & 70.524 & $-0.776^{\star * *}$ & -2.85 \\
\hline & & After & 69.748 & 70.380 & $-0.633^{\star \star}$ & -2.27 \\
\hline & \multirow{2}{*}{ Math } & Before & 70.20 & 70.397 & -0.197 & -0.72 \\
\hline & & After & 70.20 & 70.299 & -0.099 & -0.35 \\
\hline & \multirow{2}{*}{ English } & Before & 70.015 & 70.491 & $-0.476^{*}$ & -1.74 \\
\hline & & After & 70.015 & 70.307 & -0.293 & -1.03 \\
\hline \multirow[t]{6}{*}{ Kernel } & \multirow{2}{*}{ Chinese } & Before & 69.748 & 70.524 & $-0.776^{\star \star \star}$ & -2.85 \\
\hline & & After & 69.748 & 70.531 & $-0.783^{\star \star \star}$ & -2.81 \\
\hline & \multirow{2}{*}{ Math } & Before & 70.20 & 70.397 & -0.197 & -0.72 \\
\hline & & After & 70.20 & 70.410 & -0.210 & -0.75 \\
\hline & \multirow{2}{*}{ English } & Before & 70.015 & 70.491 & $-0.476^{*}$ & -1.74 \\
\hline & & After & 70.015 & 70.482 & $-0.467^{*}$ & -1.65 \\
\hline \multirow[t]{6}{*}{ Mahalanobis } & \multirow{2}{*}{ Chinese } & Before & 69.748 & 70.524 & $-0.776^{\star \star \star}$ & -2.85 \\
\hline & & After & 69.748 & 70.895 & $-1.147^{\star \star \star}$ & -4.05 \\
\hline & \multirow{2}{*}{ Math } & Before & 70.20 & 70.397 & -0.197 & -0.72 \\
\hline & & After & 70.20 & 70.598 & -0.398 & -1.36 \\
\hline & \multirow{2}{*}{ English } & Before & 70.015 & 70.491 & $-0.476^{*}$ & -1.74 \\
\hline & & After & 70.015 & 70.705 & $-0.690^{* *}$ & -2.48 \\
\hline
\end{tabular}

Notes: $1 .{ }^{*} P<0.1,{ }^{* *} P<0.05,{ }^{* * *} p<0.01$.

deduction, and other cognitive abilities of school-aged children. Therefore, the negative effect of computer use on Math performance was not from technology itself, but from the occupation of effective learning time. Finally, it should be noted that the results of Radius (Caliper) Matching, Kernel Matching and Mahalanobis Matching estimations were similar to k-nearest neighbor matching, which verified the robustness of the estimation of the study. But the ATT of Math and English were not significant in statistics, the possible reason for this may be due to the small sample size of the control group, i.e., the families with computers only account for $8.5 \%$ in the total sample, which reduced the significance of the estimation results.

\section{The Effect of the Internet on Academic Achievement}

Based on the effect of computer on academic achievement, we adopted the four matching strategies mentioned above to explore the effect of internet (including computer) on children's academic achievements, so as to clarify whether there was a differentiated effect of computer and internet use on academic achievements. As the families that with internet account for $60.8 \%$ of the total sample, which was much higher than those with computers only $(8.5 \%)$. In order to ensure both groups have equated sample size after 
Table 6. The Impact of Internet on Academic Performance.

\begin{tabular}{|c|c|c|c|c|c|c|}
\hline Strategy & Score & Type & Treated & Control & ATT & T-stat \\
\hline \multirow[t]{6}{*}{ k-nearest Neighbor } & \multirow{2}{*}{ Chinese } & After & 70.572 & 70.279 & $0.293^{*}$ & 1.89 \\
\hline & & Before & 70.567 & 70.883 & -0.316 & -1.22 \\
\hline & \multirow{2}{*}{ Math } & Before & 70.359 & 70.413 & -0.055 & -0.35 \\
\hline & & After & 70.356 & 71.392 & $-1.036^{* \star *}$ & -3.92 \\
\hline & \multirow{2}{*}{ English } & Before & 70.570 & 70.263 & $0.307^{*}$ & 1.96 \\
\hline & & After & 70.565 & 71.391 & $-0.826^{* * *}$ & -3.10 \\
\hline \multirow[t]{6}{*}{ Radius } & \multirow{2}{*}{ Chinese } & Before & 70.572 & 70.279 & $0.293^{*}$ & 1.89 \\
\hline & & After & 70.567 & 70.796 & -0.229 & -0.95 \\
\hline & \multirow{2}{*}{ Math } & Before & 70.359 & 70.413 & -0.055 & -0.35 \\
\hline & & After & 70.356 & 71.327 & $-0.971^{* \star \star}$ & -3.98 \\
\hline & \multirow{2}{*}{ English } & Before & 70.570 & 70.263 & $0.307^{*}$ & 1.96 \\
\hline & & After & 70.565 & 71.141 & $-0.577^{* *}$ & -2.37 \\
\hline \multirow[t]{6}{*}{ Kernel } & \multirow{2}{*}{ Chinese } & Before & 70.572 & 70.279 & $0.293^{*}$ & 1.89 \\
\hline & & After & 70.567 & 70.731 & -0.164 & -0.70 \\
\hline & \multirow{2}{*}{ Math } & Before & 70.359 & 70.413 & -0.055 & -0.35 \\
\hline & & After & 70.356 & 71.248 & $-0.892^{\star \star \star}$ & -3.77 \\
\hline & \multirow{2}{*}{ English } & Before & 70.570 & 70.263 & $0.307^{*}$ & 1.96 \\
\hline & & After & 70.565 & 71.071 & $-0.506^{\star *}$ & -2.14 \\
\hline \multirow[t]{6}{*}{ Mahalanobis } & \multirow{2}{*}{ Chinese } & Before & 70.572 & 70.279 & $0.293^{*}$ & 1.89 \\
\hline & & After & 70.572 & 70.841 & -0.269 & -1.13 \\
\hline & \multirow{2}{*}{ Math } & Before & 70.359 & 70.413 & -0.055 & -0.37 \\
\hline & & After & 70.359 & 71.275 & $-0.917^{\star \star \star}$ & -3.79 \\
\hline & \multirow{2}{*}{ English } & Before & 70.570 & 70.263 & $0.307^{*}$ & 1.96 \\
\hline & & After & 70.570 & 71.151 & $-0.581^{\star *}$ & -2.32 \\
\hline
\end{tabular}

matching, we used the four matching strategies mentioned above to improve the significance of the ATT. The estimated results were reported in Table 6.

In overall, the ATT of internet use on all subjects were negative after matching, and with exception of Chinese score, both math and English scores were statistically significant, which means that internet use inhibits children's academic achievements. Specific to different disciplines, the negative effect of internet on Chinese performance fell within to the range of $[-0.164,-0.316$. , Math [-0.892, -1.036] and English [-0.506, 0.826]. These indicated that internet use had the most significant negative effect on the improvement of Math performance, followed with English and then Chinese. Meanwhile, in contrast to the estimation results given in Table 5, the negative effect of internet use on academic achievements was somewhat eliminated in Chinese and English, but expanded in Math than computer use only. The estimated results confirmed the hypothesis - the negative effects of information technology usage on different disciplines were different in mechanism. Specifically, for liberal arts (Chinese and English), it indirectly changes the way of reading and habits by means of technological change. But for science (Math), it further strengthens the computer/internet entertainment preference, directly changing the time distribution of effective learning. 
Table 7. The Impact of Internet on School-age Children's Academic Performance in Urban and Rural Areas (Intra-Group Differences).

\begin{tabular}{|c|c|c|c|c|c|c|c|c|c|c|}
\hline \multirow{2}{*}{ Score } & \multicolumn{5}{|l|}{ Urban } & \multicolumn{5}{|l|}{ Rural } \\
\hline & Type & Trtd. & Ctrl. & ATT & $t$ & Type & Trtd. & Ctrl. & ATT & $t$ \\
\hline \multirow[t]{2}{*}{ Chinese } & Before & 70.75 & 69.91 & $0.834^{* * *}$ & 3.10 & Before & 70.32 & 70.41 & -0.089 & $\overline{-} .43$ \\
\hline & After & 70.74 & 70.82 & -0.078 & $\overline{0} .20$ & After & 70.32 & 70.82 & $-0.502^{*}$ & $\overline{1.82}$ \\
\hline \multirow[t]{2}{*}{ Math } & Before & 70.59 & 69.89 & $0.691^{* *}$ & 2.54 & Before & 70.03 & 70.59 & $0.565^{\star \star \star}$ & $-\overline{2.70}$ \\
\hline & After & 70.58 & 71.15 & -0.571 & $\overline{1.40}$ & After & 70.03 & 71.36 & $1.332^{\star \star \star}$ & 4.72 \\
\hline \multirow[t]{2}{*}{ English } & Before & 70.99 & 70.13 & $0.858^{* * *}$ & 3.23 & Before & 69.97 & 70.31 & -0.341 & $\begin{array}{l}- \\
1.61\end{array}$ \\
\hline & After & 70.98 & 71.24 & -0.263 & 0.66 & After & 69.96 & 71.18 & $1.223^{\star \star *}$ & 4.31 \\
\hline
\end{tabular}

Notes: $1 .{ }^{*} P<0.1,{ }^{* *} P<0.05,{ }^{* *} p<0.01$. Trtd: Treated; Ctrl: Control.

For the estimated value of ATT, internet highlighted students' entertainment preference in the process of information technology usage, so it had a higher negative effect on Math scores than computer did. On the contrary, internet use objectively broadened the channels for children to obtain effective information, improved their knowledge level such as reading and understanding abilities. That was the reason why the Internet had a weaker negative effect on Chinese and English performance than sole computer. Finally, the estimation results of computer and internet were integrated to answer the first question raised in this study: With the rapid development of information technology, the popularization of computer and the continuous increasing of internet access rate, the use of information technology by families failed to improve their children's academic achievements. In contrast, the computer and internet use caused a decline in Chinese, Math, and English scores. Our results were similar to that reported by Chen et al. (2017).

\section{Urban and Rural Sub-Sample Regression}

For the total sample, we estimated the effect of internet on the academic achievements of urban and rural children by using the k-nearest neighbor matching strategy. Table 7 presents the estimated results of the differences between the urban and rural subgroups. In terms of urban sub-samples, the estimated value of the ATT was negative indicating that compared with the control group, internet use inhibited the academic achievements of urban children, and the inhibitory effect on Chinese, math, and English scores were $0.078,-0.571$, and -0.263 , respectively. Among them, the math performance was the most obviously affected. For the rural sub-samples, the effect of internet on students' academic achievements was also negative, and the inhibitory effect on Chinese, math, and English performance were $-0.502,-1.332$, and -1.223 , respectively, and this negative impact of internet use on math was greater than Chinese and English.

The estimated results of rural-urban sample regression answered the second hypothesis of this study. To a certain extent, the information technology usage has 
Table 8. The Impact of Internet on School-Age Children's Academic Performance in Poor and Non-Poor Families (Intra-Group Differences).

\begin{tabular}{|c|c|c|c|c|c|c|c|c|c|c|}
\hline \multirow{2}{*}{ Score } & \multicolumn{5}{|c|}{ Poor Sample } & \multicolumn{5}{|c|}{ Non-poor Sample } \\
\hline & Type & Trtd. & Ctrl. & ATT & $t$ & Type & Trtd. & Ctrl. & ATT & $t$ \\
\hline \multirow{2}{*}{ Chinese } & Before & 70.66 & 70.28 & $0.372^{* *}$ & 2.27 & Before & 70.18 & 70.17 & 0.009 & 0.01 \\
\hline & After & 70.63 & 70.99 & -0.361 & 1.45 & After & 70.18 & 71.03 & -0.849 & 0.96 \\
\hline \multirow{2}{*}{ Math } & Before & 70.48 & 70.39 & 0.084 & 0.51 & Before & 69.81 & 71.03 & $-1.215^{\star}$ & $\overline{1.71}$ \\
\hline & After & 70.45 & 71.32 & $\overline{0} .866^{\star * *}$ & 3.42 & After & 69.81 & 72.31 & $2.505^{\star \star *}$ & 2.79 \\
\hline \multirow[b]{2}{*}{ English } & Before & 70.62 & 70.27 & $0.358^{* \star}$ & 2.18 & Before & 70.31 & 70.19 & 0.128 & 0.18 \\
\hline & After & 70.60 & 71.25 & $\overline{0.652^{* * *}}$ & 2.59 & After & 70.30 & 71.45 & -1.143 & $\overline{1} .23$ \\
\hline
\end{tabular}

Notes: $1 .{ }^{\star} P<0.1,{ }^{\star \star} P<0.05,{ }^{\star * *} p<0.01$. Trtd: Treated; Ctrl: Control.

caused decline in academic achievements in both urban and rural school-aged children, but no significant statistical difference was observed. For the absolute value, the negative impact of internet use on rural children was greater than the urban peers. Possible reason for this phenomenon was that the education level of urban parents was generally higher than rural parents. The average education level of father and mother from urban area were 5.138 and 4.749, respectively, which showed that fathers' average education level were senior high school (vocational high school) and mothers' were secondary school/technical school. The average education level of father and mother from rural area were 5.138 and 4.749, respectively, which showed that fathers' average education level was in the range of junior high school to secondary school/technical school and mothers' was in the range of primary school to junior high school. Higher education level helps parents control their children's entertainment preference when they use internet as well as guide their learning preference in time. This is the reason why the absolute value of negative impact of internet use on academic achievements of children from urban families was lower than that of rural families.

\section{Poverty and Non-Poverty Sub-Sample Regression}

We used family economic status to distinguish poverty and non-poverty families, and adopted the k-nearest neighbor matching strategy to estimate the impact of internet use on the academic achievements of school-aged children with different family economic conditions (Table 8). For the estimated value of ATT, no significant difference was found between internet users and non-users in both poverty and non-poverty families. The academic achievements of the treatment group were significantly lower than the control group indicating that internet use inhibits children's academic achievements, and the inhibitory effect on the math performance was higher than on Chinese and English. This was similar to that obtained by full-sample regression that verified the robustness of our study. For the absolute value of the estimate, the negative impact of internet on children who came from the better family economic status was higher than the comparisons. Taking math scores as an example, the inhibitory effect of internet on its per- 
formance was -0.866 in the poverty children, but was 0.866 in the non-poverty children. One possible reason was that children from poverty families were more sensitive to academic pressure and family economic conditions than those from non-poverty families. In the poverty group, $36 \%$ children felt academic pressure, but about $31.5 \%$ in nonpoverty children. Children from poverty families could convert the academic pressures and the perception of family economic conditions into learning motivation. Consequently, they actively suppress the entertainment preference and use internet as a learning assistant. As the proverb says, "Poverty children are more independent". Therefore, the negative impact of internet use on poverty children was less significant than the nonpoverty comparison.

\section{Conclusions and Discussion}

\section{Conclusions}

Our study was based on the China Education Panel Survey data provided by the NSRC. In the context of the continuous popularity of computers and internet, we used the method of quasi-experimental of PSM to find the net effect of information technology on academic achievements.

It was indicated that:

- There is difference in Chinese, math, and English. Chinese scores in the two grades (7 versus 9) were slightly better than Math and English. The academic achievements of urban students were better than the rural peers, especially in English. It illustrated that the unbalanced distribution of urban and rural education resources in quantity and quality is the major reason leading to significant difference in the quality of education between urban and rural areas. However, there was no positive correlation between the education achievements and the family economic status.

- Based on the Logit conditional probability model, we found that there was a positive correlation between the family's human capital stock and the information technology use. The probability of internet use increased by $3 \%$ and $3.1 \%$, respectively, for each education level of the parents. Each one-unit increase in children's perception of family's poverty status reduced the probability of internet use by $22.2 \%$. The probability value of internet use of one-child family was higher than non-one-child family by $9.7 \%$.

- We found that the use of information technology inhibited children's academic achievements, but the underlying mechanisms were different in different subjects based on the PSM. For liberal arts (Chinese and English), it works indirectly by changing the way of children's reading and habits, but for science (Math), it works by taking away effective learning time. The entertainment preference was the basic cause of the negative impact. At the same time, ignoring the differences in family and individual characteristics led to selective bias and counterfactual bias, which resulted in overestimation of the negative impact of internet on the academic achievements. 
- Sub-sample regressions showed a negative impact of information technology on school-aged children's academic achievements in both urban and rural, poverty and non-poverty samples. Guidance, moderation and regulation of parents' education to entertainment preference as well as children's perception of both academic pressure and family economic status were the leading causes of the differences between urban and rural, poverty and non-poverty children.

\section{Discussion}

This empirical study on the influence of information technology on school-age children's academic performance has essential implications for policy makers. As a means of teaching assistance, the application and popularization of computer and internet, theoretically, should help to improve students' academic outcomes. However, our empirical study found that the information technology has not effectively promoted the academic achievements, no matter in urban or rural areas, or from poor or non-poor families. This conclusion obviously contrasted to the initial intention of education informatzation, i.e. the information technology had a negative impact on school-age children's academic achievements. The reason is majorly due to students' two preferences for the computer and internet use - either learning or entertainment. Given children in grades 7 and 9 are still in the formation and development period of cognitive and non-cognitive abilities, which means their self-control ability is weak ( $\mathrm{Li}$, et al., 2017; Li, et al., 2017; Wang, et al., 2017; Yang, 2018). When they use internet, they are more likely to be dominated by the preference of entertainment, which weakens and restrains their learning preference.

In response to the reasons mentioned above, we suggest following three aspects below to make a full use of information technology to improve the quality of school education and narrow the "digital divide" in the context of education informatization. First, as a micro-field of educational activities, parents should not only provide the hardware of computer and internet for their school-aged children, but also devote themselves to cultivating the ability to distinguish their preference to entertainment and learning in the application of information technology. In addition, parents should replan and rationally allocate children's entertainment time during their working day, and help their children to form good learning habits and point of view on information technology. Second, as a medium of education activities, innovation of teaching model (such as the combination of "online" and "offline learning") should be encouraged to stimulate children's learning interest. Meanwhile, school and teachers should manage the network teaching in a reasonable way by providing a civilized and ordered network teaching environment as well as preventing the negative phenomena, such as network violence, network uncivilization, and addiction. Third, as a macro field, education activities should give priority to rural area to reduce the unbalanced distribution of educational resources between urban and rural areas, and pay more on the construction of education information system in rural schools, so as to eliminate the "digital gap". Moreover, corresponding administrative measures should be introduced at the policy aspect to ensure a reasonable advancement of information teaching. 
It should be pointed out that the marginal contribution of this study is that we estimated the "net effect" of the information technology on the academic achievements in school-aged children by using PSM to reduce the selective bias. However, there are additional two points need to be expanded further in this field. First, guide children to prefer to learn when they use computers and internet and restrain the entertainment preference using reasonable time planning. The next focus should set on the causal relationship between the rational use of information technology and academic performance. It is also the profound requirement that improves educational quality, as the education informatization going forward to the next new era. Second, are there any other effects of information technology on the academic achievements in school-age children? For example, information technology functions as an intermediary variable, either positively intervening or negatively inhibiting the development of cognitive and non-cognitive abilities of school-aged children to affect their academic achievements. Therefore, it would be another beneficial effect to discuss further the mediating role of information technology in promoting the cognitive/non-cognitive ability and academic performance, and clearly depict the differentiated effect of computer and internet on students' development, and provide information support and decision-making basis for the input of national, school and family education resources.

\section{References}

Abadie, A. \& Imbens, G. (2006) Large sample properties of matching estimators for average treatment effect. Econometrica, 74(1):235-267.

Chen, C.J. \& Gu, X.Q. (2017) The impact of information technology on students' literacy: a perspective on education informatization. Open Edu Res, 3:37-49.

Chen, C.J. \& Zhi, T.J. (2016)The impact of information technology on students' digital reading achievement: evidence from PISA. Open Edu Res, 4:57-70.

Chen, Q.L. \& Zhang, W.H. (2016) Digital divide and students' academic performance - a study based on the data from PISA2012 Shanghai. Youth Res, 3:49-56.

Dimaggio, P. \& Hargittai, E. (2001). From the "digital divide" to "digital inequality". Working paper series NO.15 Princeton University.

Fang, C. \&Huang, B. (2018) Influence of human capital investment on children's academic achievement-analysis of multilevel liner model based on CEPS tracking data. J Anhui Nor Univ (Hum. \& Soc. Sci.), 2:116-124.

Golder, S.A. \&Mary, M.W. (2014) Digital footprints: opportunities and challenges for online social research. Annual Review of Sociology, 40(1):129-152.

Gu, X.Q., Wang, C.L. \&Wang, F. (2017) Historical mission and roles of ICT in educational reform in the past 20 years. E-Edu Res, 6:919.

Hanushek, E.A. (1992) The Trade-off between Child Quantity and Quality. J Pol Eco, 100(1):84-117.

Li, L., Zhao, W.L. \&Bian, W.J. (2017) Family background the non-cognitive skills. Dongyue Tribune, 1:45-52.

Liu, X.R., Ren, Q., Li, F. \& Zhao, J. (2018) Entering a new era: history achievement, challenges and reform strategies of information technology education in elementary and middle schools of China. Modern Edu Tech, 6:17-24. 
OECD. (2015) Students, computers and learning: making the connection. Paris: OECS Publishing.

Rosenbaum, P.R. \& Rubin, D.B. (1985) Constructing a control group using multivariate matched sampling methods that incorporate the propensity score. Am Statistician, 24(4):521-544.

Wang, H.M., Wu, Y.X. \& Huang, C. (2017) Family socioeconomic status, preschool education and adolescents' cognitive \& noncognitive abilities. Youth Res, 6:46-57+92.
Xin, T. \& Zou, D. (2010) The impact of computer use in class on junior high school students' math achievement. J Edu Stud, 4:6570.

Yang, P. \& Xu, Y. (2017) Digital divide and inequality in household investment. Peking Univ Edu Rev, 4:126-154.

Yang, Z.C. (2018) The intermediary factors of family background affects the students' development. Chin EcoN Edu Rev, 3:61-82.

The Chinese version of this article has been published in Open Edu Res 2018; 6:88-99. The English version has been authorized for being publication in BECE by the author $(s)$ and the Chinese journal.

方超, 黄斌. 信息技术促进了学生的学业表现吗?一基于中国教育追踪调查数据的实证研 究. 开放教育研究, 2018; 6:88-99. 